\title{
Status Report on
}

Activities of the Systems Assessment Task Force, OECD-NEA Expert Group on Accident Tolerant Fuels for LWRs

Shannon M. Bragg-Sitton

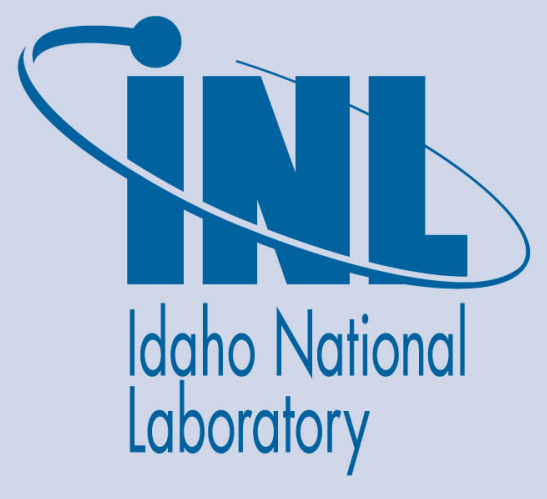

September 2015

The INL is a U.S. Department of Energy National Laboratory operated by Battelle Energy Alliance 


\section{DISCLAIMER}

This information was prepared as an account of work sponsored by an agency of the U.S. Government. Neither the U.S. Government nor any agency thereof, nor any of their employees, makes any warranty, expressed or implied, or assumes any legal liability or responsibility for the accuracy, completeness, or usefulness, of any information, apparatus, product, or process disclosed, or represents that its use would not infringe privately owned rights. References herein to any specific commercial product, process, or service by trade name, trade mark, manufacturer, or otherwise, does not necessarily constitute or imply its endorsement, recommendation, or favoring by the U.S. Government or any agency thereof. The views and opinions of authors expressed herein do not necessarily state or reflect those of the U.S. Government or any agency thereof. 


\title{
Status Report on Activities of the Systems Assessment Task Force, OECD-NEA Expert Group on Accident Tolerant Fuels for LWRs
}

\author{
Shannon M. Bragg-Sitton
}

September 2015

\author{
Idaho National Laboratory \\ Idaho Falls, Idaho 83415 \\ http://www.inl.gov
}

Prepared for the

U.S. Department of Energy

Office of Nuclear Energy

Under DOE Idaho Operations Office

Contract DE-AC07-05ID14517 
INL/EXT-15-36491 


\section{Status Report on the Activities of the Systems Assessment Task Force, OECD-NEA Expert Group on Accident Tolerant Fuels for LWRs}

\section{INTRODUCTION}

The Organization for Economic Cooperation and Development /Nuclear Energy Agency (OECD/NEA) Nuclear Science Committee approved the formation of an Expert Group on Accident Tolerant Fuel (ATF) for LWRs (EGATFL) in 2014. Chaired by Kemal Pasamehmetoglu, INL Associate Laboratory Director for Nuclear Science and Technology, the mandate for the EGATFL defines work under three task forces: (1) Systems Assessment, (2) Cladding and Core Materials, and (3) Fuel Concepts. Scope for the Systems Assessment task force (TF1) includes definition of evaluation metrics for ATF, technology readiness level definition, definition of illustrative scenarios for ATF evaluation, parametric studies, and selection of system codes. The Cladding and Core Materials (TF2) and Fuel Concepts (TF3) task forces will identify gaps and needs for modeling and experimental demonstration; define key properties of interest; identify the data necessary to perform concept evaluation under normal conditions and illustrative scenarios; identify available infrastructure (internationally) to support experimental needs; and make recommendations on priorities. Where possible, considering proprietary and other export restrictions (e.g., International Traffic in Arms Regulations), the Expert Group will facilitate the sharing of data and lessons learned across the international group membership. The Systems Assessment task force is chaired by Shannon Bragg-Sitton (INL), while the Cladding Task Force will be chaired by a representative from France (Marie Moatti, Electricite de France [EdF]) and the Fuels Task Force will be chaired by a representative from Japan (Masaki Kurata, Japan Atomic Energy Agency [JAEA]). This report provides an overview of the Systems Assessment task force charter and status of work.

\section{SYSTEMS ASSESSMENT TASK FORCE SCOPE}

Scope for the EGATF Systems Assessment task force includes definition of evaluation metrics for ATF, technology readiness level definition, definition of illustrative scenarios for ATF evaluation, parametric studies, and selection of system codes. Sub-tasks have been grouped to manage the amount of work and to provide clear deliverables at the end of each year of work. During the 2-year mandate for the Expert Group, two deliverable reports will be completed, including:

1. Evaluation Metrics and Technology Readiness Level Definition (Target: September 2015)

2. ATF Evaluation - Selected Illustrative Scenarios, Applicable Codes and Parametric Studies (Target: September 2016)

The following sections provide the current outline for each deliverable and status toward completion.

\subsection{Deliverable 1: Evaluation Metrics and Technology Readiness Level Definition}

The first deliverable that will be issued by the Systems Assessment task force is targeted for completion at the end of the first year of the expert group work, $\sim$ September 2015. Initial direction on this deliverable was given in the task force charter and is summarized below:

i. Deliverable Report: Targeted for September 2015

ii. Evaluation Metrics 
a. Task force members will provide input to define a set of evaluation metrics that can be commonly applied within all member countries to provide clear understanding of the potential enhancements to performance and safety, and potential development and/or operational risks, associated with candidate ATF designs (fuel and cladding).

b. The task force will begin by reviewing the evaluation metrics proposed within the U.S. for evaluation of ATF concepts intended for application in pressurized or boiling water reactors. It is anticipated that these metrics will be modified such that they are applicable to all participating nations.

\section{iii. Technology Readiness Level (TRL) Definition}

a. Fuel-specific TRLs will be defined to allow a common understanding of the development status of proposed ATF concepts across all countries participating in ATF development.

b. Work will begin by reviewing available TRL definitions, such as those produced within the U.S., U.K. and by the NEA Innovative Fuels Expert Group.

At the March 2015 meeting of the Task Force assignments were made to draft sections of the deliverable report, which will then be reviewed by the full task force. Ten attendees from France, Japan, Republic of Korea, Russian Federation, Sweden, Switzerland, United Kingdom and United States participated in the task force meeting.

\section{Evaluation Metrics}

The ATF performance metrics and evaluation approach proposed within the U.S. were presented at the September 2014 EGATFL meeting as a starting point for an international set of ATF performance and evaluation metrics. This approach is documented in detail in FCRD-FUEL-2013-000264 (INL/EXT-1329957).

One of the task force members from AREVA (France) presented the approach that is being used for ATF cladding evaluation in France at the March 2015 EGATFL task force meeting. AREVA is currently using a 2 -step evaluation process for cladding evaluation:

1. Standardised tests to compare concepts under normal and accident conditions

○ Nominal conditions (Corrosion, Mechanical Properties)

- Corrosion:

- ASTM G2: $400^{\circ} \mathrm{C}$ steam for 3 days and 14 days

- PWR water chemistry: $360^{\circ} \mathrm{C}$ long-term autoclave test (up to 240 days)

- Mechanical properties:

- Internal pressure test: 1 and $2 \%$ deformation at $400^{\circ} \mathrm{C}\left(\right.$ and $20^{\circ} \mathrm{C}$ )

- Tensile test: at room temperature $\left(20^{\circ} \mathrm{C}\right)$ and $400^{\circ} \mathrm{C}$

- Internal pressure creep test: at room temperature $\left(20^{\circ} \mathrm{C}\right)$ and $400^{\circ} \mathrm{C}$

○ Accident conditions

- High temperature one-sided steam oxidation at $1200^{\circ} \mathrm{C}$ for 600 s (with postquench mechanical evaluation by Ring Compression Test)

- Dynamic internal pressure high temperature ballooning and burst test

2. Concept-specific feasibility assessment, focusing on potential "show stoppers" specific to each candidate.

In the discussion that followed the French presentation, emphasis was placed on defining reference tests applicable to all materials to allow for direct comparison of candidate materials. Another key item of investigation is the adherence between coatings and the base material (to be tested in corrosion tests at high temperature, $\sim 2000^{\circ} \mathrm{C}$ ). For alternative types of fuels (i.e. uranium nitride/silicide), evaluations 
should include mechanical testing and fuel and fission product washout from a leaking rod at high temperature. The AREVA representative is currently preparing an initial draft of the cladding metrics for the international document that will be issued by NEA.

Japan has also begun preparation of a set of performance metrics for use within Japan, but this activity has been somewhat delayed due to settling of details within Japan on the development of ATF. Japanese representatives volunteered to prepare the first draft of fuel metrics for the NEA document.

\section{Technology Readiness Levels}

Similarly, definition of technology readiness levels (TRLs) for fuel and cladding were presented at the March 2015 EGATFL meeting by representatives from the U.S., the U.K., and Japan; the TRL definition report issued by the NEA Expert Group on Innovative Fuels was also summarized.

The Working Party on Fuel Cycle (WPFC) Expert Group on Innovative Fuels issued a definition of Technology Readiness Level (TRL) applicable to fuels for transmutation purposes. This information is included in the state-of-the-art report published in 2014 (available at this link https://www.oecdnea.org/science/pubs/2014/6895-report-innovative-fuels.pdf ). This definition addresses both fabrication and in-pile fuel performance maturity, with values ranging from 1 to 9 and covering 4 phases from research and development to full industrial operation:

- Selection Phase: TRL 1 - 3;

- Development Phase: TRL 3 - 5;

- Optimisation Phase: TRL 5 - 7;

- Qualification Phase: TRL 7 - 9.

The specificity of the analysis carried out by the Innovative Fuels Expert Group was to take into account all possible combinations for fabrication (materials quality, materials quantity) and in-pile performance (test environment, test size), leading to a quite complete characterisation of possible levels of maturity. A general agreement emerged during the task force discussion, concluding that the definition elaborated by the Innovative Fuels Expert Group may easily be applied to ATF candidates, with only few adaptations needed.

The U.S. defines TRLs for both performance maturity and fabrication maturity, each of which is measured on a scale from 1 to 9, very similar to what was presented for the Innovative Fuels Expert Group. The Japanese and British TRL definitions, as presented at the March 2015 meeting, are also quite similar. However, the Japanese and British approaches appear to link the performance and fabrication maturity into a single TRL, ranging from 1 to 9 for Japan and 1 to 10 for the U.K. A specific feature of the Japanese approach is the attempt to deal not only with design, reprocessing, fuel manufacturing and fuel performance, but to include far-reaching issues including fuel safety, licensing, specifications / standards, storage, and transportation. The U.K. TRL discussion provided a review of worldwide international experience available, not limited to ATF but involving current and near term reactors (Gen. II, III, III+, and Light Water Small Modular Reactors) and Gen IV reactors. The ensuing discussion highlighted the fact that TRLs are reactor-dependent; e.g., the same fuel and/or cladding materials may exhibit a different TRL depending on the reactor in which it is to be applied.

The National Nuclear Laboratory (NNL, U.K.) representative on the systems assessment task force volunteered to draft a common set of TRLs for the EGATFL document, merging the approaches presented by NNL, the NEA Expert Group on Innovative Fuels, and Japan. The initial draft of the planned deliverable report will be prepared and distributed to the task force members within the first week of 
September 2015, allowing for distribution to the task force in advance of the NEA EGATFL meeting planned for September 17-18, 2015. Preliminary review of the document will be conducted at the September 2015 meeting. A target for the final submission of the NEA deliverable will be set at that meeting. The outline of the deliverable is included as Appendix A in this report.

\subsection{Deliverable 2: ATF Evaluation - Selected Illustrative Scenarios, Applicable Codes and Parametric Studies}

The second deliverable that will be issued by the Systems Assessment Task Force is targeted for completion at the end of the second year of the expert group work, S September 2016. Initial direction on this deliverable was given in the task force charter and is summarized below:

i. Deliverable Report: Targeted for September 2016

ii. Definition of Illustrative Scenarios for ATF Evaluation

a. The task force members will propose key illustrative scenarios that can be applied to evaluate the performance of candidate ATF designs. Scenarios should not be overly prescriptive or specific to a particular facility design.

b. Preliminary suggestions for illustrative scenarios include:

(1) Simplified case in which the accident conditions are unmitigated (allowed to continue "forever," e.g. to the point of system failure)

(2) High pressure and low pressure scenarios

iii. Identify Available Fuel Performance and System Codes

a. Fuel performance and system codes that can be used to evaluate accident tolerant fuel performance, can be modified to evaluate ATF concepts, or are under development. Current limitations of the identified codes and data required to run these codes should be identified.

b. The availability of the identified codes to other companies or nations should be clarified.

iv. Perform Parametric Studies

a. Conduct preliminary parametric analyses using the available system and fuel performance codes for the selected illustrative scenarios to identify whether or not similar trends appear for each code.

b. Parametric studies are not intended to benchmark codes, but to find common ground across these codes. The resultant deliverable report is not intended to draw conclusions, but rather to define analysis processes that can be employed to evaluate ATF performance against the established metrics.

A more detailed plan for the completion of this milestone, including assignment of preliminary authorship for each section, will be established at the September 2015 EGATFL meeting. Discussions at the March 2015 task force meeting introduced each of the topics that will be covered in the deliverable document; these discussions are summarized below.

\section{Definition of Illustrative Scenarios}

In defining illustrative scenarios for evaluation of ATF concepts, the following principles were agreed upon by the task force members:

- Scenarios should be simple in nature. Station blackout is a likely case.

- Models should allow the accident conditions to continue to the point of fuel failure.

- It may be appropriate to consider both high pressure and low pressure scenarios.

- The impact of availability of cooling for some time (e.g. $72 \mathrm{hrs)} \mathrm{after} \mathrm{a} \mathrm{scram} \mathrm{should} \mathrm{be}$ investigated. 
Discussions at the task force meeting covered possible accident scenarios / sequences for PWR, BWR and VVER reactor designs. General agreement was reached on two scenarios applicable to general reactor designs:

- Station Blackout: High pressure scenario; take to the point of RPV failure

- Large-break Loss of Coolant Accident (LOCA): Low pressure scenario (high decay heat at loss of coolant)

Additional discussion points applicable to these scenarios are as follows:

- Simulation scenarios should be taken to the point of core failure.

- Pressure is very important to the accident progression.

- Participants should recall that the evaluation process is not to compare reactors, but to compare fuel/cladding systems.

- Scenario evaluation should provide bounding cases.

Parametric studies of accident scenarios can be performed based on the time at which cooling is lost after reactor scram.

\section{Fuel Performance and System Codes}

An overview of fuel performance and system analysis codes currently being used in the U.S. for evaluation of performance under normal operating conditions and accident conditions was presented at the March 2015 meeting. A standard suite of tools is used for initial screening analyses, including infinite lattice calculations to estimate basic concept feasibility and three-dimensional core analysis to assess thermal hydraulics, temperature feedback, etc. Work is currently being conducted in the U.S. to develop advanced modelling and simulation tools and to incorporate ATF properties and behavioural characteristics. Additionally, existing severe accident analysis tools are being modified to incorporate ATF characteristics. Although some of the tools are limited in fidelity, particularly with regard to ATF concepts for which little property and behavioural data is available, they do provide initial estimates of performance for these concepts

Discussion among the task force participants identified additional codes that are being utilized outside of the U.S. Department of Energy research program. Many of these tools are limited in their application to ATF concepts at this time, but additional data that will be made available from ongoing research programs will significantly enhance these capabilities. In many cases companies and organizations select their own internal tools to perform fuel performance, system, and severe accident analyses. Much of the discussion focused on severe accident analysis modelling, which has employed MELCOR and MAAP (with modification of property details required for ATF evaluation). Fuel performance codes range across countries. It is anticipated that each of these tools will be utilized in ATF analysis depending on the preference of a particular country or organization. The overall trends observed for materials using these different codes should be studied; the EGATFL task force activities will not attempt to benchmark codes against one another.

\section{Parametric Studies}

Only preliminary discussions have been held within the Systems Assessment task force to date. Two possible approaches to a parametric study have been discussed:

- Variation of key fuel/cladding properties: It is currently unclear as to which EGATFL task force may conduct these studies - (1) Systems Assessment; (2) Cladding; or (3) Fuels. 
- Variation of illustrative scenario conditions with set properties:

- These types of studies provide bounding conditions for design.

- A suggestion was made to vary key parameters, including time of an accident occurrence relative to fuel burnup, initial decay heat, time available for cooling, etc.

Possible parametric studies will be further discussed at the September 2015 EGTFL meeting.

\section{SUMMARY}

This report provides an update on the activities conducted within the Systems Assessment task force (TF1) for the OECD/NEA Expert Group on Accident Tolerant Fuels for LWRs. Note that the remaining task forces within the EGATFL on Cladding and Core Materials (TF2) and Fuel Concepts (TF3) will each produce a state-of-the-art report on the materials under development across the NEA member countries and involved observer countries (e.g. China). These state-of-the-art reports are targeted for completion in $\sim$ September 2016. 


\section{Appendix A}

Outline of Deliverable 1

Light Water Reactor Accident Tolerant Fuel:

Evaluation Metrics and Technology Readiness Level Definition 


\section{INTRODUCTION}

2. ATF DESIGN CONSTRAINTS AND DESIRED ATTRIBUTES

3. DEFINITION OF EVALUATION METRICS and RELATED TESTING

\subsection{Cladding Materials}

3.1.1. Desired performance, properties, behavior

3.1.1.1. Normal operation

3.1.1.2. Accident performance

3.1.2. Proposed standard tests, noting possible differences for each cladding type (coated, ceramic, metallic)

3.1.2.1. Corrosion

3.1.2.2. Mechanical properties

3.1.2.3. Accident behavior

\subsection{Fuel Materials}

3.2.1. Desired performance, properties, behavior

3.2.1.1. Normal operation

3.2.1.2. Accident performance

3.2.2. Proposed standard tests

3.2.2.1. Corrosion

3.2.2.2. Mechanical properties

3.2.2.3. Accident behavior

3.3. Considerations for the Fuel / Cladding System

3.3.1. Mechanical and/or chemical interactions

3.3.2. Standard tests, including irradiation testing protocol

4. APPLICATION OF EVALUATION METRICS / PATH FORWARD

4.1. Key considerations for each "performance regime"

4.1.1. Fabrication

4.1.2. Normal operations

4.1.3. Design basis accidents

4.1.4. Beyond design basis accidents

4.1.5. Used fuel storage, transportation, disposition

4.2. Definition of suggested weighting factors for performance attributes in each performance regime

5. DEFINITION OF TECHNOLOGY READINESS LEVELS

6. REFERENCES 